\title{
SOBRE ESTRATEGIA: ASPECTOS A CONSIDERAR PARA LA CONCEPCIÓN, DECLARACIÓN, EJECUCIÓN Y EVALUACIÓN DE UNA ESTRATEGIA
}

\author{
About Strategy: aspects to consider for the conception, declaration, execution and evaluation \\ of a strategy \\ Iván Vera Paucar 1, Е \\ 1 Dirección de Planificación y Desarrollo Universitario, Universidad Andina del Cusco, Cusco, Perú. \\ a Bachiller en Administración de Empresas \\ झ ivera@uandina.edu.pe
}

Citar como: Vera, I. (2018). Sobre estrategia: aspectos a considerar para la concepción, declaración, ejecución y evaluación de un estrategia. Rev Yachay, 7(1), 454-463.

Recibido: 16-09-2018; Aceptado 07-12-2018

\section{Introduccion}

La estrategia es un tema tratado en múltiples esferas, pero principalmente en el ámbito de los negocios y el militar. En el presente escrito abordaremos la estrategia desde un enfoque de negocios o empresarial, considerando aspectos operativos de su implementación y formulación, así como temas que se relacionan con este. Se rescatan argumentos de algunos de los escritores y académicos más reconocidos sobre el tema y, en base a sus opiniones, buscaremos consensuar criterios que permitan definir y utilizar la estrategia de manera más efectiva.

El documento está compuesto por cinco puntos. El primer punto aborda lo referente a la definición de estrategia desde la perspectiva de las organizaciones o empresas, aquí se analizan las definiciones de D’alessio (peruano), Fred David, Collis y Montgomery, Villajuana (peruano), Mintzberg y Quinn, y Porter, y se finaliza con una definición de estrategia que busca integrar todas las definiciones presentadas.

En el punto dos, se desarrollan los elementos de una declaración de estrategia, donde básicamente se establecen los tres componentes de la redacción de una estrategia: objetivo, alcance y ventaja. En el punto tres se desarrollan aspectos que deben considerase para la implementación de una estrategia sin salirse del marco de la responsabilidad social. El punto cuatro, trata sobre la implementación de las estrategias y el medio ambiente: se hacen algunas precisiones legales y se muestran algunas ideas que pueden ser utilizadas para no generar un conflicto entre ambas. Finalmente, en el punto cinco se desarrollan los tipos de estrategias que pueden implementarse en una organización, la clasificación abarca: estrategias genéricas, la estrategia del océano azul, y estrategias alternativas.

\section{Definición de 'estrategia'}

Hablar de estrategia es un tema complejo, puesto que existen múltiples ámbitos en los que es usado y aplicado el término y, por consiguiente, definido de una forma particular para cada caso. Centraremos nuestra atención en los conceptos y definiciones aplicables a los negocios y planeamiento estratégico.

D’Alessio (2013, págs. 8-9) cita a Hax y Majluf (1991), y señala que estos autores desarrollaron un conjunto de formas bajo las cuales puede ser entendida la estrategia, siendo estas: 1) es un patrón de decisiones coherente, unificado e integrador; 2) es un medio para establecer el propósito de la organización en términos de objetivos a largo plazo, programas de acción y priorización en la asignación de recursos; 3) es una respuesta a las oportunidades y amenazas externas, basada en las fortalezas y debilidades internas para alcanzar ventajas competitivas. 
Las dos últimas formas de entender la estrategia son adecuadas para llevar a cabo un proceso estratégico y formular las estrategias a través de la muy conocida «Matriz de Fortalezas, Oportunidades, Debilidades y Amenazas (MFODA)» pero, desde nuestro punto de vista, entenderlo así es, aunque muy operativo, tomar a la estrategia muy a la ligera.

Fred David (Conceptos de Administración Estratégica, 2008, pág. 13), es uno de los autores más citados en el ámbito académico a la hora de hablar de administración estratégica; él señala que «las estrategias son los medios por los cuales se logran los objetivos a largo plazo», y estas están definidas por «acciones potenciales que requieren de decisiones de los altos directivos y de grandes recursos de la empresa». En su explicación del concepto señala: que las estrategias afectan la prosperidad de la organización a largo plazo, por esta razón son orientadas hacia el futuro. Dada la naturaleza multidivisional y multifuncional de la estrategia, esta requiere que, para su formulación, se consideren tanto factores internos como externos.

Por su lado Collis y Montgomery (Competir con los recursos, 2008, pág. 10), mencionan que «las buenas estrategias corporativas requieren de la constante reevaluación del alcance de la empresa», y deben intentar apalancar los recursos en todos los mercados en los que estos aporten ventaja competitiva o impulsarlos a competir en nuevos mercados que mejoren los recursos corporativos Villajuana (2009, pág. 84) afirma que «la estrategia se refleja en la elección del destino de los recursos más importantes, de la ventaja competitiva que se creará y de lo que se hará para fortalecer la ventaja competitiva». Queda claro entonces, que las estrategias son necesarias para alcanzar la visión a través de los objetivos a largo plazo y requieren del compromiso de la alta dirección, a fin de que se tomen las decisiones correctas y se asignen los recursos necesarios y suficientes para su implementación. Además, deben ser formuladas realizando un análisis del entorno e intorno de la organización que permita identificar los factores que influyen en esta.

Henry Mintzberg y James Brian Quinn (1993, pág. 5), hacen mención a varias definiciones de estrategia. Quinn, señala que la estrategia es un «patrón o plan que integra a las principales metas y políticas de una organización, y, a la vez, establece la secuencia coherente de las acciones a realizar»; Mintzberg por su parte va más allá, y presenta cinco definiciones de estrategia: como plan, pauta de acción, patrón, posición y perspectiva; siendo las definiciones:

- Estrategia como plan y pauta de acción. Bajo esta perspectiva, la estrategia «es un plan, una especie de curso de acción consciente determinado, una guía (o conjunto de guías) para abordar una situación específica», pudiendo ser estas generales o específicas. Señala que, como plan, «una estrategia también puede ser una pauta de acción, una "maniobra" para ganar la partida al contrincante o competidor». (Ibíd., págs. 14 - 15).

- La estrategia como patrón. Esta definición parte del hecho de que no es suficiente definir la estrategia como un plan, también es necesario definirla desde el comportamiento que deseamos que produzca. Bajo esta perspectiva la «estrategia es un modelo, específicamente un patrón en un flujo de acciones»; en otros términos, nos referimos a que la estrategia tiene que ver con la «consistencia en el comportamiento, tanto si es intencional como si no lo es». (Ibíd., pág. 15).

- La estrategia como posición. Esta definición está orientada a señalar para qué sirve la estrategia, siendo compatible con definiciones anteriores. Se asume que «la estrategia como posición, en particular, es un medio para ubicar una organización en lo que los teóricos de la organización suelen llamar 'medio ambiente'; siendo esta la fuerza mediadora entre la organización y el 'medio ambiente'», o sea, entre el contexto interno y externo de la organización (Ibíd., pág. 18). En otras palabras: la estrategia nos servirá para generar posicionamiento a través de lo que Michael Porter llama 'ventaja competitiva'.

- La estrategia como perspectiva. La definición de estrategia como perspectiva, apunta hacia el interior de la organización, debido a que el contenido de una estrategia «implica no solo la selección de una posición, sino una manera particular que percibir el mundo», esto significa que la estrategia está sostenida en la competencia distintiva de la organización, en su razón de ser. Es así que coincidimos con la analogía que señala que «la estrategia es para la organización, lo que la personalidad es para el individuo» (Ibíd., pág. 19). Bajo esta percepción la estrategia nos identifica, nos da la oportunidad de ser únicos como organización, nos permite innovar, crear valor, abordar y asumir los retos que se presentan en el entorno desde nuestra perspectiva, desde nuestras fortalezas y debilidades. Lo único importante aquí es que esta perspectiva sea compartida por todos los que integran la organización.

Michael Porter, en un artículo denominado «¿Qué es la estrategia?», desarrolla su concepto partiendo de una diferenciación entre eficacia operativa y estrategia, señala que la eficacia operativa o eficacia operacional es «realizar las mismas actividades mejor que los rivales», siendo el perfeccionamiento de este necesario para una rentabilidad superior, 'pero no suficiente'. Esta insuficiencia se debe a que las mejores prácticas (traducidas en técnicas y herramientas de gestión como: calidad total, benchmarking, reingeniería y otros), son copiadas rápidamente por los rivales favoreciendo a la industria pero, no a una empresa en particular. 
Afirma que una competencia basada solamente en eficacia operativa «es mutuamente destructiva y conduce a guerras de desgaste que solo se pueden detener limitando la competencia», hecho que se presenta debido a que el uso de las herramientas de gestión «conducen a las empresas a la imitación y la homogeneidad», permitiendo que la eficacia operacional suplante a la estrategia. Con esto, no quiere decir que la eficacia operacional debe dejarse de lado, sino más bien, debe ser el punto de partida para la formulación y aplicación de una estrategia que genere un posicionamiento estratégico y, por consiguiente, una ventaja competitiva sostenible en el tiempo. Afirma que la estrategia consiste en ser diferente, esto significa: «la selección deliberada de un conjunto de actividades distintas para crear una mezcla de valor único»; donde la esencia de la estrategia «radica en las actividades: ya sea realizar actividades de forma distinta o bien realizar actividades diferentes a aquellas realizadas por los rivales». Hace hincapié en el concepto de trade-offs, pues la «estrategia consiste en hacer trade-offs al competir» siendo su esencia 'elegir lo que no se hará'. Asimismo, incluye en su análisis el calce, donde se da importancia a la combinación de las actividades de la estrategia; siendo esta combinación necesaria porque «aleja a los imitadores al crear una cadena que es tan resistente como lo es su eslabón más fuerte», es así que la estrategia incluye «crear un calce entre las actividades de la empresa», donde el éxito de una estrategia consiste en hacer bien muchas cosas (no solo unas pocas) e integrarlas entre sí (Porter, 2009, pág. 69 al 107). Podríamos decir entonces, que la estrategia es distinta a la eficacia operacional y consiste en la elección (trade-offs) de actividades únicas o en la ejecución de actividades de forma distinta a los rivales, debiendo estas complementarse (calzar) y reforzarse entre sí.

Los conceptos mostrados son algunos de los más influyentes en el mundo empresarial, casi de cita obligada por quienes desean definir un concepto de estrategia y aplicarla a un proceso estratégico. Abordan la estrategia desde múltiples puntos de vista y bajo la perspectiva del ámbito en el cual será aplicado; consideramos que todos son perfectamente aplicables en la administración estratégica de una organización. Aunque en nuestra opinión, es necesaria una definición que integre las múltiples perspectivas mostradas.

Consideramos que la estrategia podría ser definida como un medio, guía o guías de actuación que permitan establecer una pauta de acción y un patrón de comportamiento estable, diseñada para posicionar a la organización (lograr una posición concreta) dentro de la industria en la que compite y generar una ventaja competitiva sostenible en el tiempo; asimismo, debe permitir el logro de los objetivos propuestos por la organización y, por consiguiente, alcanzar la visión deseada. Debe ser formulada desde la perspectiva de la organización, desde cómo esta percibe el entorno y basada en sus competencias distintivas (considerando sus fortalezas y debilidades).

Toma como punto de partida la eficacia operativa, pero es diferente de esta. Está basada en la elección (trade-offs) de actividades únicas o en la ejecución de actividades de forma distinta a los rivales debiendo estas complementarse (calzar) y reforzarse entre sí. Asimismo, su implementación requiere del compromiso de los altos directivos de la organización y de una adecuada toma de decisiones siendo necesaria también, la oportuna asignación de recursos suficientes y necesarios.

\section{Elementos de una 'declaración de estrategia'}

Después de haber abordado la definición de estrategia y sus diferentes matices; considero que es necesario tratar un aspecto algo más operativo, pero, operativo no desde el punto de vista de la implementación de la estrategia propiamente dicha, sino más bien desde lo referido a la elaboración o redacción del enunciado de estrategia.

Si bien existe mucha literatura sobre el tema, en nuestra revisión no hemos encontrado artículos o ensayos específicos que respondan a la pregunta más básica: ¿cómo describir la estrategia o las estrategias de una organización?, y con esta pregunta no nos referimos al hecho de describir los resultados que se ven o cómo esta se ejecuta, sino más bien, al hecho de cómo redactarla. Pensamos que, por las múltiples definiciones existentes, los ámbitos de aplicación así como la naturaleza única (desde su concepción y aplicación) de cada estrategia, no ha permitido llegar a un consenso sobre cómo debería ser descrita o redactada. No obstante, es necesario hacerlo debido a que definirla claramente es importante por dos razones: primero, «se hace mucho más fácil la formulación ya que los ejecutivos saben qué están intentando crear»y; segundo, «se simplifica la implementación porque la esencia de la estrategia se puede comunicar rápidamente y puede ser interiorizada con facilidad por todos dentro de la organización» (Collis y_Rukstad, 2008, pág. 2). Una declaración de estrategia comprendida por todos los integrantes de una organización permitirá alinear las conductas, y que se comiencen a tomar decisiones individuales que se refuercen entre sí, permitiendo que todos los colaboradores sean potencialmente más eficaces.

Collis y Rukstad (2008) critican el artículo ¿Qué es la estrategia?, de Michael Porter y señalan que es muy ilustrativo a la hora de exponer las características conceptuales de la estrategia, la esencia de elegir y distinguirla de la eficacia operativa, mas para ellos tiene un vacío: no nos dice cómo describirla o redactarla. Partiendo de esta crítica, estos autores han desarrollado un conjunto de elementos para describir la estrategia general de una empresa. Consideramos que ese modelo propuesto es perfectamente aplicable para la redacción o descripción de estrategias en todos los niveles de una organización. Es así que estos autores señalan que cualquier declaración de estrategia debe comenzar por una «definición de los objetivos que la estrategia se propone lograr», pues la definición de 
este objetivo «no solo debería incluir un punto de término sino también un marco temporal para alcanzarlo»; un segundo elemento tiene que ver con la industria en la que compite la organización, siendo esta amplia y abierta, es necesario definir el alcance o dominio de la organización, «la parte del paisaje en la cual operará la empresa»; el tercer y último elemento tiene que definir la ventaja competitiva, en otras palabras: lo que la empresa hará mejor o distinto al resto, «define los medios — lo esencial— mediante los cuales logrará su objetivo declarado». (Ibíd., pág. 2).

- Definición del objetivo. La mayoría de las organizaciones ya tiene definidos el o los objetivos que desea alcanzar. No obstante, muchas veces estos se definen de manera equivocada. Tenemos que tener presente que el objetivo que definamos debe ser ‘único y preciso' y debe impulsar a la organización en los próximos años, en el largo plazo. El objetivo estratégico «debe ser específico, medible y sujeto a plazos. También debería consistir en una sola meta», o desencadenar una serie de metas subordinadas al objetivo estratégico, de tal forma que estas puedan servir de indicadores en un balanced scorecard que permita controlar su progreso y hacer responsables a las personas (Collis, David; Rukstad, Michael, 2008, págs. 3-4).

- Definición del alcance. El alcance de una organización va a estar definida por tres dimensiones: compradores u oferta, ubicación geográfica e integración vertical. Definir claramente los límites, en estas áreas o dimensiones, permitirá «que para los ejecutivos sea evidente en qué actividades deberían centrarse y, más importante aún, lo que no deberían hacer». (Ibíd., págs. 4-5)

- Definición de la ventaja. Este es considerado como es aspecto más crucial de una declaración de estrategia, siendo la ventaja competitiva sustentable la esencia de la estrategia, pues «la claridad respecto a qué le da su sello distintivo a la empresa, es lo que más ayuda a los empleados a comprender cómo pueden aportar a la ejecución exitosa de su estrategia». Esta declaración de ventaja competitiva tiene dos partes: a) "una declaración de propuesta de valor", para los compradores o cliente específicamente, y b) debe "capturar las actividades únicas o la compleja combinación de actividades" que permita que solo la organización entregue la propuesta de valor declarada. (Ibíd., pág. 5). Es aquí donde el modelo se alinea con los elementos de la definición y mapa de sistemas de actividades propuesta por Michael Porter.

Desarrollar la declaración de una estrategia no es un trabajo sencillo, pues implica hacer cuidadosamente los análisis pertinentes (interno y externo). Además, en su concepción existe un componente creativo que debe «encontrar el lugar ideal donde las capacidades de la empresa, se alineen con las necesidades del cliente de una manera tal que los competidores no puedan igualar en un contexto externo cambiante». (Ibíd., pág. 7). Desarrollar una estrategia y luego elaborar una declaración que capture su esencia de forma simple y fácil de comunicar debe involucrar a todos los integrantes de la organización, debe ser producto de un debate y la uniformización de criterios sobre los términos más adecuados a utilizar.

\section{Estrategia y responsabilidad social}

Para dialogar de estrategia y responsabilidad social, necesariamente, debemos hablar de un concepto inherente a estos dos términos, el llamado "valor compartido":

[...] está definido como las políticas y las prácticas operacionales que mejoran la competitividad de una empresa, a la vez que ayudan a mejorar las condiciones económicas y sociales en las comunidades donde opera. La creación de valor compartido se enfoca en identificar y expandir las conexiones entre los progresos económico y social. (Porter, M., y Kramer, M., 2011a, pág. 3).

Los autores señalan que existen tres formas de crear valor compartido: a) preconcibiendo productos y mercados, b) redefiniendo la productividad en la cadena de valor y, c) construyendo clusters de apoyo para el sector, en torno a las instalaciones de la empresa. El concepto implica que ambos lados (empresa y sociedad) se beneficien. Bajo esta premisa procuraremos en este punto, ver cuál es el papel de la estrategia en la creación de valor, en otras palabras, qué aspectos abordar o a dónde debe apuntar una estrategia para contribuir a que la organización sea responsable socialmente.

Existen múltiples debates (aún inacabados) sobre la llamada responsabilidad social corporativa (RSC), nuestro interés al tocar este tema no es entrar en ese debate, sino más bien, asumir una postura y ver las implicancias que tiene con respecto a la estrategia. Es así que cuatro argumentos son los más usados para justificar la RSC: obligación moral, sustentabilidad, licencia para operar y reputación.

- Obligación moral. Bajo este argumento se asume que la empresa "debe ser una buena ciudadana y hacer lo correcto". No obstante, las obligaciones morales son, por naturaleza, mandatos absolutos, mientras que las decisiones de RSC "implica equilibrar valores, intereses y costos en conflicto" (Porter, M., y Kramer, M., 2006a). 
- Sustentabilidad. Aquí se enfatiza la "tutoría medioambiental y comunitaria". Este argumento obliga a las organizaciones a alcanzar un triple resultado en su desempeño: económico, social y ambiental. Esto significa que las organizaciones deben funcionar en «modalidades que garanticen el desempeño económico a largo plazo, evitando las conductas de corto plazo socialmente prejudiciales o ambientalmente despilfarradoras». (Ibíd. 2006a, pág. 6).

- Licencia para operar. Esta noción se deriva de que toda organización necesita «permiso tácito o explícito de los gobiernos, comunidades y muchos stakeholders para hacer negocios» o funcionar; aunque este enfoque es más práctico porque ofrece una manera concreta de que una organización identifique problemas sociales importantes para sus stakeholders y decida sobre ellos. Su problema radica en que al tratar de satisfacer a estos, las organizaciones, «ceden el control primario de sus agendas de RSC a agentes externos». Esto no significa que debamos restarles interés a las opiniones de los stakeholders, pero debemos ser conscientes de que estos grupos nunca comprenderán plenamente las capacidades y el posicionamiento competitivo de una organización o las concesiones que este debe hacer para satisfacerlos. Asimismo, el que un grupo de interés señale un problema, esto no significa necesariamente que este sea importante para la organización. (Ibíd. 2006a).

- Reputación. Esta resulta ser una justificación de la organización para realizar actividades de responsabilidad social, bajo el argumento que «mejorarán la imagen de una empresa, fortalecerán su marca, elevarán la moral e incluso, incrementarán el valor de sus acciones» pero, esto usualmente no ocurre; este beneficio estratégico rara vez ocurre. La reputación, al igual que la licencia para operar, están enfocados para satisfacer a audiencias externas a la organización. (Ibíd. 2006a).

Como se aprecia, los cuatro argumentos enfocan la tensión existente entre una organización y la sociedad, sin considerar su interdependencia siendo esta su debilidad principal. Cada uno crea una lógica general aislada de la estrategia, de las operaciones de la organización y, del entorno donde esta compite. Por esta razón, estos cuatro argumentos no son suficientes para ayudar a la organización a definir, identificar, priorizar y abordar los problemas más relevantes de la sociedad, aquellos en los que su contribución sería mayor y más efectiva. No podemos definir una estrategia en función solo a estos argumentos.

Habíamos señalado que, para la adecuada formulación de una estrategia, es necesario hacer un buen análisis de los entornos interno y externo de la organización, no siendo una excepción en el caso de integrar el aspecto social de manera más explícita. Para desarrollar estrategias socialmente responsables, es necesario prestar especial atención a los vínculos de adentro hacia afuera y a los vínculos de afuera hacia adentro, pues, dada la interdependencia existente entre organización y sociedad, se debe garantizar la buena salud del contexto competitivo que beneficie a ambas partes.

A la hora de vincular la estrategia y la responsabilidad social es necesario tomar en cuenta:

- Elegir qué temas sociales abordar. Ninguna organización es capaz de abordar todos los problemas sociales existentes, ni mucho menos el costo que implica abordarlos. Es necesario hacer una selección de los problemas sociales que convergen con la razón de ser de la organización, para que puedan representar una oportunidad para crear valor compartido. Según el marco de referencia de Porter y Kramer (2006), los problemas sociales que afectan a una organización se dividen en tres categorías: 1) problemas sociales genéricos, que pueden ser importantes para la sociedad, pero no se ven influidos significativamente por las operaciones de la empresa ni afectan a la competitividad en el largo plazo; 2) impactos sociales de la cadena de valor, se refiere a problemas que surgen debido a que la sociedad se ve altamente influida por las actividades de la empresa, en condiciones normales de funcionamiento; 3 ) dimensiones sociales del contexto competitivo, se refiere a problemas s ociales que afectar significativamente a los impulsores subyacentes (básicos) de la competencia en los lugares donde la organización funciona (Ibíd., 2006a pág.8). Usando estos criterios, se deberá ubicar cada problema social en alguna de estas categorías y clasificar según el impacto potencial de cada uno, y así tomar una mejor decisión. No olvidar que la ubicación de cada problema social, en alguna de las categorías, dependerá de la razón de ser de la organización, de las actividades principales que realiza; variando su importancia de acuerdo al contexto competitivo, posicionamiento estratégico, la industria, y la organización o unidad organizacional que abordará el problema.

- Crear una agenda de responsabilidad social corporativa (RSC). Clasificar los problemas sociales, bajo los criterios señalados, tiene como fin la creación de una agenda de responsabilidad social corporativa, que nos permita pasar de «mitigar el daño a buscar maneras de reforzar la estrategia corporativa mediante el progreso social», en otras palabras: pasar de una responsabilidad social corporativa reactiva (RSC reactiva) a una responsabilidad social corporativa estratégica (RSC estratégica). La RSC reactiva comprende básicamente dos elementos: a) actuar como buen ciudadano corporativo, de acuerdo con las cambiantes inquietudes sociales de los stakeholders, y b) mitigar los efectos adversos actuales o previstos de las actividades de la organización.

\footnotetext{
Rev. Yachay volumen (7) Número (1), enero-diciembre 2018
} 
La RSC estratégica va más allá de las mejores prácticas (eficacia operativa), pues ocurre cuando una organización añade una dimensión social a su propuesta de valor, convirtiendo el impacto social en una parte integral de la estrategia. (Ibíd., 2006a págs.12-13).

Lo expuesto nos deja más claro el cómo deberíamos integrar la estrategia y la responsabilidad social. Al hacerlo de esta forma, tenemos más posibilidades de crear valor compartido, pues al invertir (ya habíamos señalado en el punto uno de este ensayo que la estrategia significa invertir recursos) en aspectos sociales, es posible fortalecer la competitividad de la empresa y desarrollar una relación simbiótica donde el éxito de la empresa y el de la sociedad se refuerzan mutuamente.

Integrar en la estrategia las necesidades sociales y de la organización, no solo requiere de buenas intenciones y liderazgo fuerte sino, además, se necesita ajustes en la estructura de una organización, las relaciones jerárquicas y hasta incentivos que la potencien. No olvidemos que la "estructura sigue a la estrategia", eso significa que, sí o sí debe generarse un cambio importante en la organización, siendo la responsabilidad social corporativa un aspecto crucial, que debe ser integrado y hecho operativo durante la formulación de la estrategia, pues no solo implica cumplir con la exigencia social sino, que además, puede ser una fuente de ventaja competitiva sostenible, un ingrediente de diferenciación.

\section{Estrategia y medio ambiente}

Uno de los argumentos expuestos al tratar la RSC es la sustentabilidad, esta busca que la organización logre un triple resultado: económico, social y ambiental; esto significa que el aspecto ambiental es parte de la responsabilidad social, y este debe ser tratado a la hora de describir o redactar la estrategia siguiendo las recomendaciones ya expuestas. No obstante, debido a la importancia y relevancia actual del aspecto ambiental, hemos visto conveniente desarrollarlo más ampliamente en este punto.

El nuestro país, el tema medioambiental, está reglamentado. La Ley General del Ambiente - Ley N. ${ }^{\circ} 28611$ (publicada el 15 de octubre de 2005), señala que «toda persona tiene el derecho irrenunciable a vivir en un ambiente saludable, equilibrado y adecuado para el pleno desarrollo de la vida, y el deber de contribuir a una efectiva gestión ambiental y de proteger el ambiente» (Ministerio del Ambiente, 2005, pág. 20), bajo esta premisa, establece los principios y normas básicas para asegurar el efectivo ejercicio del derecho a gozar de un ambiente saludable, así como contribuir a una efectiva gestión ambiental y proteger el medio ambiente. Del mismo modo, dentro del ámbito de su aplicación hace mención a que:

Las disposiciones contenidas en la presente Ley, así como en sus normas complementarias y reglamentarias, son de obligatorio cumplimiento para toda persona natural o jurídica, pública o privada, dentro del territorio nacional, el cual comprende el suelo, subsuelo, el dominio marítimo, lacustre, hidrológico e hidrogeológico y el espacio aéreo.

La presente Ley regula las acciones destinadas a la protección del ambiente que deben adoptarse en el desarrollo de todas las actividades humanas. La regulación de las actividades productivas y el aprovechamiento de los recursos naturales se rigen por sus respectivas leyes, debiendo aplicarse la presente Ley en lo que concierne a las políticas, normas e instrumentos de gestión ambiental. (Ministerio del Ambiente, 2005, pág. 23).

La ley establece que, tanto personas naturales como jurídicas, entidades públicas y privadas, que se encuentren dentro del territorio nacional deben cumplir con lo que la norma establece. Esta norma establece las acciones destinadas a la protección de medio ambiente en todas las actividades humanas, incluyendo las actividades productivas y de aprovechamiento de recursos naturales (en el ámbito de su aplicación).

Como se aprecia el cuidado del medio ambiente lo vemos desde el punto de vista de la RSC o desde el cumplimiento de normas legales, es un tema ineludible para cualquier organización a la hora de formular estrategias. Entramos aquí en otra disyuntiva: ¿ecología o economía? O, en términos más empresariales ¿somos verdes o somos competitivos?

A nuestro entender esta disyuntiva se genera debido a que las normas legales ambientales son aceptadas de forma general, pero al mismo tiempo con poca voluntad por cumplirlas, tanto por personas naturales como por organizaciones que desarrollan actividades productivas; por un lado: si cumplimos la norma y somos ecológicos (o verdes), es un hecho que tendremos beneficios sociales que favorecen a todos, mas, por otro lado, el cumplir las normas medioambientales suman costos o gasto de recursos que deben ser asumidos por las organizaciones a la hora de buscar prevenir la contaminación o disminuir el impacto ambiental ya generado por sus actividades productivas; costos que se verán reflejados en el precio final del producto o servicio ofrecido. 
Asimismo, existen otros dos puntos en discordia; una norma legal es generalmente estática (no cambia con facilidad), concebida en un momento y tiempo, y habiendo identificado factores que no necesariamente son estáticos; por el contrario, un ambiente competitivo tiene una dinámica industrial, donde las condiciones y factores son muy cambiantes. Con esto no queremos decir que debamos elegir entre uno de los puntos de la disyuntiva, pues, a nuestro parecer es posible elegir ambos, o sea, podemos ser verdes y competitivos, el punto donde estos dos pueden ser conciliados tiene que ver con la 'eficiencia'.

Si hablamos de contaminación podríamos afirmar lo siguiente: contaminación = ine ficiencia, esta afirmación la hacemos puesto que la principal causa de la contaminación es el desperdicio y mal manejo de recursos e insumos (muchos de ellos altamente peligrosos) pues, como dice Porter, la ineficacia en el uso de recursos es más clara en el interior de las organizaciones «cuando se traduce en la utilización incompleta de los materiales o una deficiencia en el control de los procesos, que dan como resultado desperdicios, defectos, excesos de existencia» (Porter, 2009, pág. 409), que contribuyen a la contaminación ambiental. Queda claro entonces, que el antídoto para evitar la contaminación se llama 'eficiencia'. La misma que debe ser aplicada no solo durante el proceso productivo (dentro de la empresa), sino que debe abarcar toda la cadena de valor de la organización en toda su extensión.

Pareciera que nos hemos salido del tema central de este escrito: la estrategia, pero no es así. La concepción del término y su formulación e implementación implica elegir, decidir un conjunto de actividades que debemos ejecutar (o no debemos ejecutar) para alcanzar los objetivos y, en última instancia, la visión de la organización; esta elección debe ser basada en un análisis concienzudo de todas las implicancias que esta tiene. Abordar los múltiples aspectos en que afectan el funcionamiento de la organización, como la RSC, en un aspecto un poco más específico: el cuidado del medio ambiente.

Durante la formulación e implementación de una estrategia debe estar presente a eficiencia. Toda organización debe buscar un conjunto de actividades que le permitan optimizar el uso de sus recursos, evitar desperdicios, desviaciones, pasos o tareas que no sumen al valor final que se pretende entregar a los compradores. Si toma en cuenta la eficiencia tendrá múltiples efectos favorables, tanto económicos como para el medio ambiente. Al disminuir sus costos operativos será capaz de mantener un precio adecuado para sus compradores, mejorar la calidad de sus productos (bienes o servicios), lograr un mejor posicionamiento en la industria; finalmente, ser más competitivo. Desde el punto de vista social, el menor uso de recursos significa menos contaminación ambiental, lo que implicará disminuir los costos de mitigar los efectos de su actividad productiva sobre el medio ambiente. Desde donde lo veamos ser verdes y competitivos es posible y muy favorable para la empresa es, además: rentable.

Un aspecto que no quiero dejar de lado, es que la eficiencia tiene una función más preventiva que correctiva o de mitigación en lo que se refiere al cuidado del medio ambiente. Debe estar implícita en todas las estrategias que se formulen, más eso no significa que debamos dejar de formular e implementar estrategias diseñadas específicamente para contribuir al cuidado del medio ambiente, es nuestro derecho, deber y responsabilidad hacerlo. Más, considero que estas deberán ser dirigidas explícitamente a acciones o actividades de mitigación de los impactos ya generados.

\section{Tipos de estrategias}

Ya hemos tratado algunos de los puntos más importantes sobre la definición de la estrategia, su descripción (redacción), y las consideraciones que deben ser tomadas en cuenta para que integre tanto la responsabilidad social corporativa (o empresarial), como un aspecto más específico y relevante de este, el cuidado del medio ambiente; ahora nos toca tratar lo referido a los tipos de estrategia.

Antes de comenzar la exposición de los que consideramos son los principales tipos de estrategias desarrolladas por diversos autores, es necesario señalar que, de acuerdo a la definición asumida, es posible diseñar (a través de actividades únicas) muchos tipos de estrategias, todo dependerá de la creatividad de los estrategas, la situación de la organización, las condiciones de la industria en la cual competimos, entre otros factores que son constantes.

\section{Estrategias competitivas genéricas}

Las estrategias genéricas competitivas son propuestas por Michael Porter en su libro "Ventaja competitiva", en este libro, él identifica que para lograr una ventaja competitiva sostenible se deben tomar en cuenta tanto los puntos débiles como los puntos fuertes de una organización (fortalezas y debilidades), pues estos tendrán un impacto positivo o negativo en los costes relativos o en la diferenciación, que sumado al ámbito en que una organización desarrolla sus actividades (determinado por la estructura de la industria, y analizado a través de modelo de las cinco fuerzas) da origen a tres estrategias genéricas para lograr un desempeño superior: liderazgo en costes, segmentación (concentración) en los costes y segmentación (concentración) en la diferenciación (Porter, 2013, pág. 39). 
- Liderazgo en costos globales. Consiste en alcanzar el liderazgo en costos globales "mediante un conjunto de políticas funcionales encaminadas a este objetivo básico" (Ibíd. 2013, pág. 78). Esta estrategia exige a la organización propiciar la construcción e implementación de instalaciones que permitan un uso eficiente de los recursos disponibles, así como un control riguroso de los costos fijos y variables. Si bien disminuir los costos es el objetivo, no se debe descuidar la calidad.

- Diferenciación. Como su nombre lo indica, esta estrategia consiste en «diferenciar el producto o servicio que ofrecemos, creando así algo que en toda la industria se percibe como único». (Ibíd. 2013, pág. 80). Existen muchas formas de obtenerlo: a través de diseño de productos, inversión en tecnología, mejora en las redes de distribución, entre otras. Esta estrategia es favorable para crear vínculos estrechos con los clientes (identificación) y reduce la sensibilidad al precio, aunque impide conseguir gran participación en el mercado (por apuntar a un segmento exclusivo), por no centrarse en la reducción de costos, permite obtener mayores márgenes de utilidad por producto.

- Segmentación. Esta tercera estrategia está centrada en la atención de «un grupo de cliente, en un segmento de línea de productos o en un mercado geográfico», a diferencia de las dos estrategias anteriores (cuyo impacto se prevé sea en toda industria) esta estrategia busca ante todo «dar un servicio excelente a un mercado particular y diseña estrategias funcionales teniendo presente lo anterior». (Ibíd. 2013, pág. 81). Con esta estrategia la organización busca satisfacer en un mayor grado las necesidades de sus clientes, pudiendo en un segmento específico lograr liderazgo en costos, diferenciación o ambos.

\section{La estrategia del océano azul}

Los autores de este tipo de estrategia establecen dos tipos de espacios donde puede desarrollarse una organización, lo que ellos llaman: océanos rojos y azules. Los océanos rojos «representan todos los sectores que existen hoy; el espacio de mercado conocido». Aquí, las fronteras del sector están definidas y son aceptadas por todos los competidores, las reglas de juego se entienden bien. En este tipo de entorno las organizaciones intentan superar a sus rivales apoderándose de la mayor proporción de demanda existente. Ahora bien, los océanos azules «identifican a todos los sectores que aún no existen hoy, el espacio desconocido de mercado, no contaminado por la competencia», es un espacio donde «la demanda se crea y no se disputa», por consiguiente, existe abundancia de oportunidades de crecimiento rentable y, además, rápido (Chan, Kim y Mauborgne, Renée, 2005, pág. 2). Existen dos formas de crear un océano azul:

- La primera, que muy pocas veces se da, es cuando surgen empresas que crean industrias completamente nuevas.

- La segunda, que son la mayoría de los casos, se da cuando dentro de un océano rojo, una empresa modifica las fronteras de un sector existente.

Los autores de «La estrategia del océano azul», desarrollan toda una metodología para crear estos espacios donde la competencia es irrelevante, debiendo para ello la empresa: crear un espacio de mercado no disputado, hacer que la competencia sea irrelevante, crear y capturar nueva demanda, romper el dilema de valor/costo y, alinear el sistema completo de actividades de la empresa en búsqueda de diferenciación y bajo costo. Este último punto (búsqueda de diferenciación y bajo costo) es donde la estrategia del océano azul puede funcionar como un ancla que refuerce la ejecución de las estrategias genéricas propuestas por Porter, pues en su esencia, una estrategia formulada de esta forma constituye un patrón único que representa una barrera a la imitación, ya que estará conformada por actividades únicas de creación de valor.

\section{Estrategias alternativas}

Fernando D'Alessio, expone un conjunto de estrategias a las que denomina "estrategias externas alternativas", esta denominación se deba a que son externas porque se refiere a "aquellas que debe desarrollar la organización para alcanzar la visión estratégica" y son alternativas porque "al existir un abanico de ellas, el proceso estratégico permitirá cuáles de estas estrategias se escogerán” (D’Alessio I. 2013, pág. 238). Este autor expone cuatro grupos de estrategias, siendo estas:

- Estrategias de integración. Son estrategias que tienen por objetivo lograr una integración vertical u horizontal. Dentro de las estrategias de integración vertical tenemos: a) integración vertical hacia adelante, que se consigue al ganar mayor propiedad o mayor control sobre los canales, distribuidores o minoristas; y b) integración vertical hacia atrás, a través del cual se gana propiedad o mayor control sobre los proveedores de la organización. La estrategia de integración horizontal se consigue al ganar propiedad o incrementar el control sobre los competidores.

- Estrategias intensivas o de concentración. Son un sinónimo de estrategias agresivas u ofensivas, pueden ser: a) penetración en el mercado, cuyo propósito final es aumentar la participación del mercado para los productos actuales (bienes o servicios) de la organización; b) desarrollo de mercados, que consiste en la introducción de productos (nuevos o actuales) dentro de nuevas áreas geográficas; y c) desarrollo de productos, a través de incrementar la participación en mercados actuales desarrollando nuevos productos. 
- Estrategias de diversificación. Está compuesto por estrategias enfocadas a ampliar la línea de productos de la organización, tanto hacia los productos relacionados, como a los no relacionados. Tenemos aquí: a) estrategias de diversificación concéntrica, donde se hace una diversificación de productos que se relacionen con los actuales; b) estrategias de diversificación conglomerada, que significa adicionar nuevos productos no relacionados con los actuales; y c) estrategias de diversificación horizontal, donde se adicionan productos no relacionados para los actuales consumidores.

- Estrategias defensivas. Tienen que ver con estrategias utilizadas para salvar a la organización de situaciones financieras u operativas deficientes. Podemos optar aquí por: a) aventura conjunta, donde dos o más organizaciones/unidades se unen para propósitos cooperativos únicos; b) atrincheramiento o reducción, donde la organización se reagrupa a través de la reducción de activos y costos para revertir una disminución en la participación de mercado; c) desposeimiento/desinversión, que significa venta de una parte de la organización; y d) liquidación, que significa la venta de todos los activos de la organización.

A nuestro entender, los tres grupos de estrategias mostradas (genéricas, océano azul y alternativas) son aplicables a cualquier tipo de organización, sea esta una prestadora de servicios, productora de bienes, pública, privada, con o sin fines de lucro; que compitan en una industria particular. Asimismo, pueden ser combinadas y su formulación e implementación dada en los distintos niveles organizacionales.

\section{Conclusiones}

A modo de resumen, se puede concluir lo siguiente:

- Una definición integral de estrategia podríamos decir que es un medio, guía o guías de actuación que permitan establecer una pauta de acción y un patrón de comportamiento estable, diseñada para posicionar a la organización (lograr una posición concreta) dentro de la industria en la que compite y generar una ventaja competitiva sostenible en el tiempo; asimismo, debe permitir el logro de los objetivos propuestos por la organización y, por consiguiente, alcanzar la visión deseada.

Debe ser formulada desde la perspectiva de la organización, desde cómo esta percibe el entorno y basada en sus competencias distintivas (considerando sus fortalezas y debilidades). Toma como punto de partida la eficacia operativa, pero es diferente de esta. Está basada en la elección (trade-offs) de actividades únicas o en la ejecución de actividades de forma distinta a los rivales, debiendo estas complementarse (calzar) y reforzarse entre sí.

Asimismo, su implementación, requiere del compromiso de los altos directivos de la organización y de una adecuada toma de decisiones siendo necesaria también, la oportuna asignación de recursos suficientes y necesarios.

- Desarrollar la declaración de una estrategia no es un trabajo sencillo, pues implica hacer cuidadosamente los análisis pertinentes (interno y externo). Debe incluir los elementos: objetivo, alcance y ventaja. Además, en su concepción existe un componente creativo que debe «encontrar el lugar ideal donde las capacidades de la empresa, se alineen con las necesidades del cliente de una manera tal que los competidores no puedan igualar en un contexto externo cambiante».

Desarrollar una estrategia y luego elaborar una declaración que capture su esencia de forma simple y fácil de comunicar debe involucrar a todos los integrantes de la organización, debe ser producto de un debate y la uniformización de criterios sobre los términos más adecuados a utilizar.

- Integrar en la estrategia las necesidades sociales y de la organización no solo requiere de buenas intenciones y liderazgo fuerte, sino además, se necesita ajustes en la estructura de una organización, las relaciones jerárquicas y hasta incentivos que la potencien. No olvidemos que la "estructura sigue a la estrategia", eso significa que, sí o sí, debe generarse un cambio importante en la organización siendo la responsabilidad social corporativa un aspecto crucial que debe ser integrado y hecho operativo durante la formulación de la estrategia, pues no solo implica cumplir con la exigencia social, sino que además, puede ser una fuente de ventaja competitiva sostenible, un ingrediente de diferenciación.

- Para transformar estrategias y medio ambiente, es necesario aplicar principios de eficiencia, que tiene una función más preventiva que correctiva - o de mitigación - en lo que se refiere al cuidado del medio ambiente. Debe estar implícita en todas las estrategias que se formulen mas, eso no significa que debamos dejar de formular e implementar estrategias diseñadas específicamente para contribuir al cuidado del medio ambiente, es nuestro derecho, deber y responsabilidad hacerlo. Sin embargo, consideramos que estas deberán ser dirigidas explícitamente hacia acciones o actividades de mitigación de los impactos ya generados.

- Los tres grupos de estrategias mostradas (genéricas, océano azul y alternativas) son aplicables a cualquier tipo de organización, sea esta una prestadora de servicios, productora de bienes, pública, privada, con o sin fines de lucro; que compitan en una industria particular. Del mismo modo, pueden ser combinadas y su formulación e implementación dada en los distintos niveles organizacionales. 


\section{Referencias bibliográficas}

Chan, Kim y Mauborgne, Renée. (2005). La estrategia del ocáno azul (19.a ed.). (F. B. Vélez, Ed., \& A. d. Hassan, Trad.) Bogotá, Colombia: Grupo Editorial Norma. Obtenido de http://www.sistema-secreto.com/000 descargas/La\%20Estrategia\%20de1\%20Oceano\%20Azul.pdf

Collis, D., \& Montgomery, C. (2008). Competir con los recursos. América Latina: Harvard Business Review.

Collis, David; Rukstad, Michael. (2008). ¿Puede usted decir cuál es su estrategia? Harvard Business Review, 86(4), 98-107. Obtenido de https://dialnet.unirioja.es/servlet/articulo?codigo=2556218

D'Alessio Ipinza, F. (2013). El proceso estratégico. Un enfoque de gerencia (2.da ed.). (M. F. Castillo, Ed.) Lima: Pearson Editorial de México D. F. Obtenido dehttps://issuu.com/wilmerfermincastillomarquez/docs/-el-proceso-estrategico-un-enfoque-

David, F. (2008). Conceptos de Administración Estratégica (9.a ed.). (E. Q. Duarte, Ed., \& M. Á. Carrión, Trad.) México: Pearson Educación. Obtenido de https://maliaoceano.files.wordpress.com/2017/03/libro-fred-david-9a-edicion-con-estrategica-freddavid.pdf

Hamel, G., \& Prahalad, C. (2005). Propósito estratégico. América Latina: Harvard Business Review.

Kim, C., \& Mauborgne, R. (2012). La estrategia del océano azul. Cómo desarrollar un nuevo mercado donde la competencia no tiene ninguna importancia. Colombia: Norma.

Ministerio del Ambiente. (2005). Ley General del Ambiente - Ley N. ${ }^{\circ}$ 28611. Lima, Lima, Perú: Dirección General de Politicas, Normas e Instrumentos de Gestión Ambiental. Obtenido de http://www.minam.gob.pe/wp-content/uploads/2013/06/leygeneral-del-ambiente.pdf

Mintzberg, H., \& Quinn, J. (1993). El Proceso Estratégico. Conceptos, contextos y casos (2.da ed.). (G. G. Castillo, Trad.) México DF, México: Prentice Hall Hispanoamericana, S.A. Obtenido de https://isabelportoperez.files.wordpress.com/2012/08/proceso_estrategico_mintzberg.pdf

Porter, M. ((1996) 2011). ¿Qué es la estrategia? América Latina: Harvard Business Review.

Porter, M. (2009). Ser competitivo. Barcelona, España: Deusto S.A. Ediciones.

Porter, M. (2013). Estrategia Competitiva. Técnicas para el análisis de la empresa y sus competidores. España: Ediciones Pirámide.

Porter, M. (2013). Ventaja Competitiva. Creación y sostenibilidad de un rendimiento superior. (G. Anaya, Ed.) Madrid, España:

Ediciones Pirámide.

Porter, M., y Kramer, M. (diciembre de 2006a). Estrategia y Sociedad. Harvard Business Review América Latina, 1-14.

Porter, M., y Kramer, M. (2011a). La creación de valor compartido. Harvard Business Review - América Latina, 1-18. Obtenido de http://www.filantropia.org.co/archivo/attachments/article/198/Shared\%20Value\%20in\%20Spanish.pdf

Sun-Tzu, \& Lawson, J. (2012). El arte de la guerra para ejecutivos y directivos. España: Ediciones Obelisco.

Villajuana, C. (2009). Los 7 tejidos estratégicos. Un plan sin indicadores es como un cuerpo sin alma. Perú: Fondo Editorial Universidad de Ciencias y Humanidades. 